\title{
Humidity Sensor Based on Multi-Walled Carbon Nanotube Thin Films
}

\author{
C. L. Cao, ${ }^{1,2}$ C. G. Hu, ${ }^{1}$ L. Fang, ${ }^{1}$ S. X. Wang, ${ }^{1}$ Y. S. Tian, ${ }^{2}$ and C. Y. Pan ${ }^{2}$ \\ ${ }^{1}$ Department of Applied Physics, Chongqing University, Chongqing 400044, China \\ ${ }^{2}$ Department of physics, Chongqing Communication College, Chongqing 400035, China
}

Correspondence should be addressed to C. L. Cao, caochunlan0812@163.com and C. G. Hu, hucg@cqu.edu.cn

Received 26 April 2010; Accepted 1 September 2010

Academic Editor: Teng Li

Copyright (C) 2011 C. L. Cao et al. This is an open access article distributed under the Creative Commons Attribution License, which permits unrestricted use, distribution, and reproduction in any medium, provided the original work is properly cited.

\begin{abstract}
The properties of the humidity sensors made of chemically treated and untreated multi-walled carbon nanotube (MWCNT) thin films are investigated systematically. It shows that both the chemically treated and untreated MWCNT thin films demonstrate humidity sensitive properties, but the former have stronger sensitivity than the latter. In the range of $11 \%-98 \%$ relative humidity $(\mathrm{RH})$, the resistances of the chemically treated and untreated MWCNT humidity sensors increase $120 \%$ and $28 \%$, respectively. Moreover, the treated humidity sensors showed higher sensitivity and better stability. In addition, the response and recover properties, and stabilization of the humidity sensors are measured, and the humidity sensitive mechanisms of the sensors are analyzed. The humidity sensitivity of carbon nanotube thin films indicates it promise as a kind of humidity sensitive material.
\end{abstract}

\section{Introduction}

Humidity sensors are widely applied in process control, environment monitoring, storage, electrical devices, and so forth, and the research to develop some new materials for sensor device attracts more and more attention. Carbon nanotubes (CNTs) is a kind of carbon allotrope, which was found in 1991 by Iijima [1]. Owing to its very large surface area to volume ratio [2], nanoscale structure and hollow center, CNTs can absorb large amounts of foreign molecules on its surface [3]. With the presence of these molecules, many properties associated with CNTs would change. Due to these reasons nanotubes have been explored for many sensors [4-6]. Zahab et al. [7] reported that water vapor has a great effect on the electrical conductivity of a singlewalled carbon nanotube (SWCNT) mat, and p-type carbon nanotube would turn into n-type if water molecules added. It means that CNTs may be a kind of humidity sensing materials. Some studies of humidity sensitivity on SWCNTs have been reported [7, 8], and Varghese et al. [5], Valentini et al. [6], and Cantalini et al. [9] have investigated the gas sensitive characteristics of MWCNTs systematically and observed humidity sensitivity of MWCNTs briefly, and they have found that the humidity sensor impedance increases with increasing humidity $[5,6,9]$. But the humidity sensitive properties of MWCNTs have seldom been studied deeply and systematically.

Here we report the humidity sensing properties of both untreated and chemically treated MWCNT thin films systematically, including the sensitivity, the response and recover properties, and stabilization. The different properties of the two types of sensors are compared and the humidity sensing mechanisms of the sensors are discussed.

\section{Experimental}

In this experiment, carbon nanotubes were produced by hot filament chemical vapor deposition (CVD) [10] using $\mathrm{C}_{2} \mathrm{H}_{2}$ and $\mathrm{Ni} / \mathrm{Fe}$ as the carbon source and catalyst, respectively. The obtained carbon nanotubes were characterized by the scanning electron microscopy (SEM) and transmission electron microscopy (TEM).

The CNTs used to prepare the humility sensors were classified into two types, untreated and chemically treated sample, respectively. In the chemical treatment process, MWCNTs were undergone a ultrasonic treatment for 150 minutes in a mixture of $98 \%$ sulphuric acid and $79 \%$ nitric 


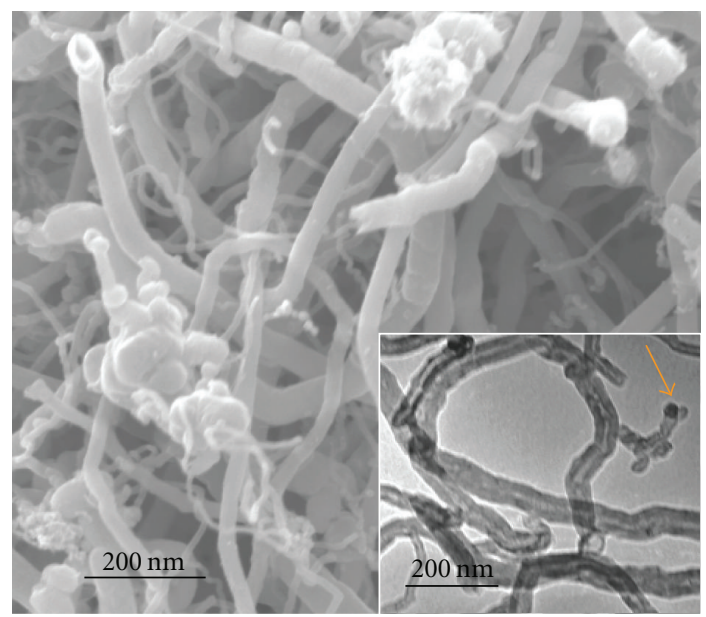

(a)

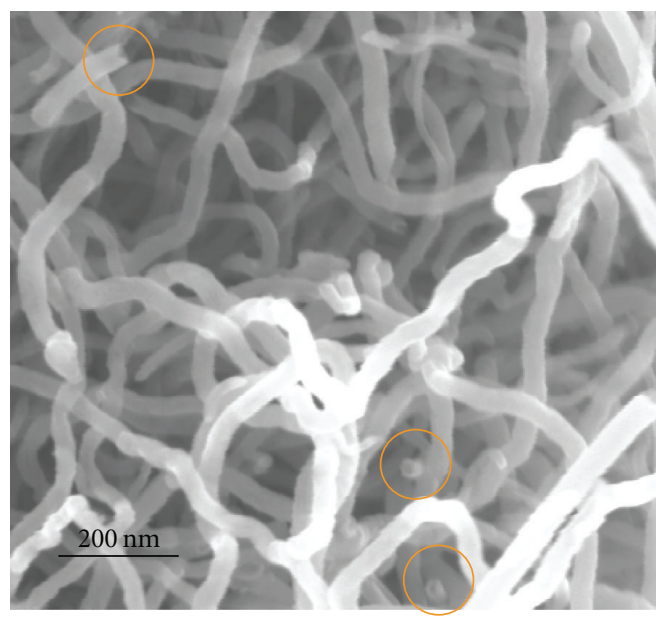

(b)

FIGURE 1: SEM images of pristine (a) and chemically treated (b) carbon nanotubes, and TEM image of carbon nanotubes (inset).

acid in ratio of $3: 1$. The treated nanotubes were rinsed in deionized water and then let to dry. The thin films of humidity sensors are prepared by spraying on top of predeposited Au electrodes on quarts plate using an airbrush with untreated and chemically treated MWCNTs dispersed in ethanol, respectively. The dimensions of samples were $1 \times$ $10^{-2} \mathrm{~m}$ in length, $5 \times 10^{-3} \mathrm{~m}$ in width, and $1 \times 10^{-4} \mathrm{~m}$ in thickness.

The electrical characteristic of the sensors were measured by a multifunctional digital multimeter (FLUKE-45 model, made in the US America) at variant humidity environments at constant temperature $\left(20^{\circ} \mathrm{C}\right)$. The sensors were successively put into several chambers with different RH levels obtained by saturation salt solution method. $\mathrm{RH}$ values varied from $11 \%$ to $98 \%$. The uncertainty of the $\mathrm{RH}$ values is about $\pm 1 \%$. All samples were dried at $373 \mathrm{~K}$ for 30 minutes prior to electrical measurements. The measurement was done after 30 minutes when the temperatures inside and outside the chambers became the same.

\section{Results and Discussion}

3.1. Microstructure. Figures 1(a) and 1(b) show the SEM images of the pristine and the chemically treated carbon nanotubes. From the SEM images, the diameter of carbon nanotubes ranges from 40 to $60 \mathrm{~nm}$. TEM image of the pristine carbon nanotubes is shown in the inset, indicating tube-like morphology. Before chemical treatment, carbon nanotubes are impure with some carbon particles, and some ends of the nanotubes are closed as is pointed by the arrow. However, after chemical treatment, the carbon nanotubes are more pure, and almost all the ends of the nanotube are open (marked in circles).

3.2. Humidity-Resistance Characteristic. Figures 2(a) and 2(b) give the D.C. resistance versus RH plots of untreated and treated MWCNT humidity sensors, respectively. The solid lines in the figures are measured in the humidification process (increasing $\mathrm{RH}$ ), corresponding to the adsorption process, while the dashed lines are measured in the desiccation process (decreasing $\mathrm{RH}$ ), corresponding to the desorption process. It shows that the resistance of both the untreated and treated samples changes almost linearly with the relative humidity. When $\mathrm{RH}$ increases from $11 \%$ to $98 \%$, the resistance of the untreated and treated samples increases $28 \%$ and $120 \%$, respectively, means, the treated samples have stronger sensitivity than the untreated.

The sensitivity factor $S$ can be defined as

$$
S=\frac{R_{\mathrm{RH}}-R_{0}}{R_{0}} \times 100 \%,
$$

where $R_{\mathrm{RH}}$ and $R_{0}$ are the resistance in the humidity state and $11 \% \mathrm{RH}$, respectively.

As shown in Figure 3, the sensitivity factor $S$ increases linearly with RH, and can be fitted linearly to (2) and (3) for the untreated and chemically treated MWCNTs humidity sensor, respectively,

$$
\begin{aligned}
& S=-4.70+0.32 * \mathrm{RH}, \\
& S=-15.47+1.34 * \mathrm{RH} .
\end{aligned}
$$

It can be seen that the slope of chemically treated MWCNTs humidity sensor (1.34) is far greater than that of untreated MWCNTs humidity sensor (0.32), meaning that the sensitivity of the former is much higher than the latter. The higher sensitivity of the chemically treated sensor is attributed to its purity of nanotubes and higher surface sites available for the adsorption of water molecules resulting from its shorter length and more open ends.

However, a hysteresis of resistance versus $\mathrm{RH}$ in the desiccation process (Figure 2) is found in both chemically treated and untreated sensors. This is probably due to the different 


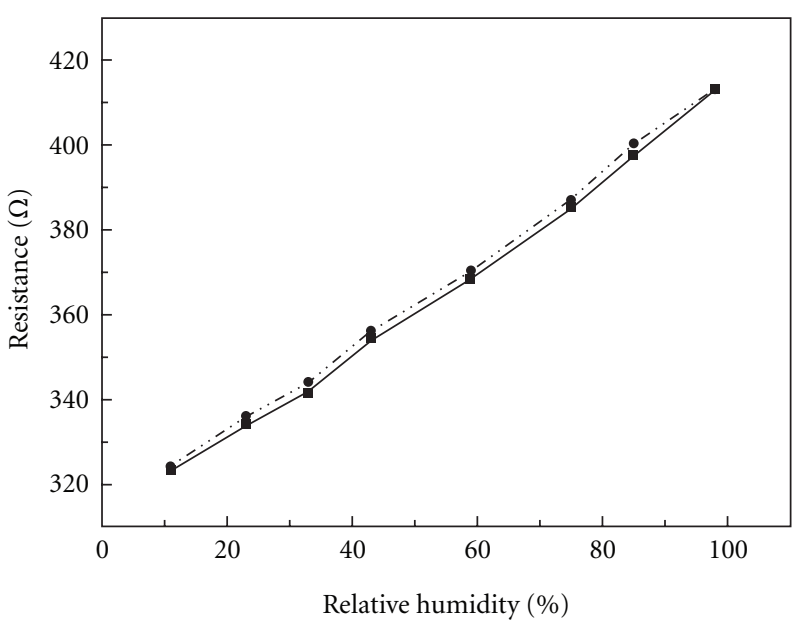

(a)

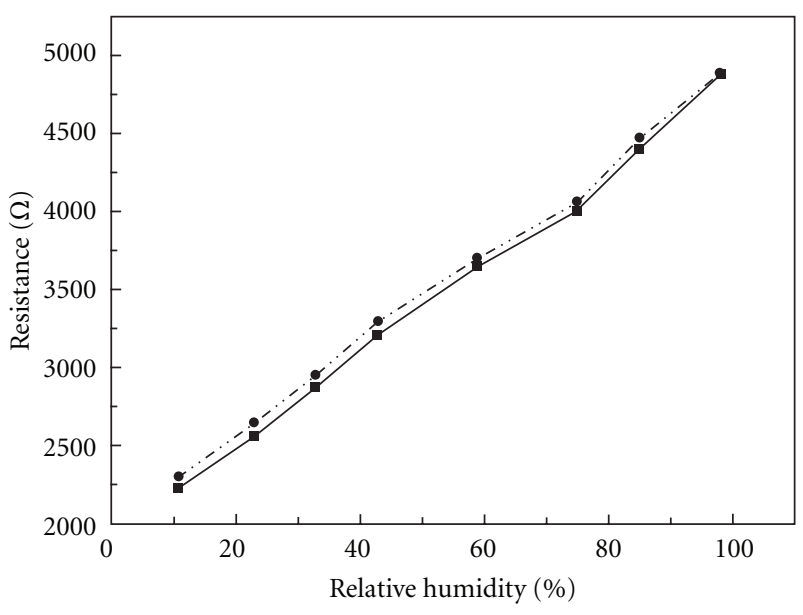

(b)

FIGURE 2: Resistance versus RH characteristics of (a) untreated and (b) treated MWCNT humidity sensors.

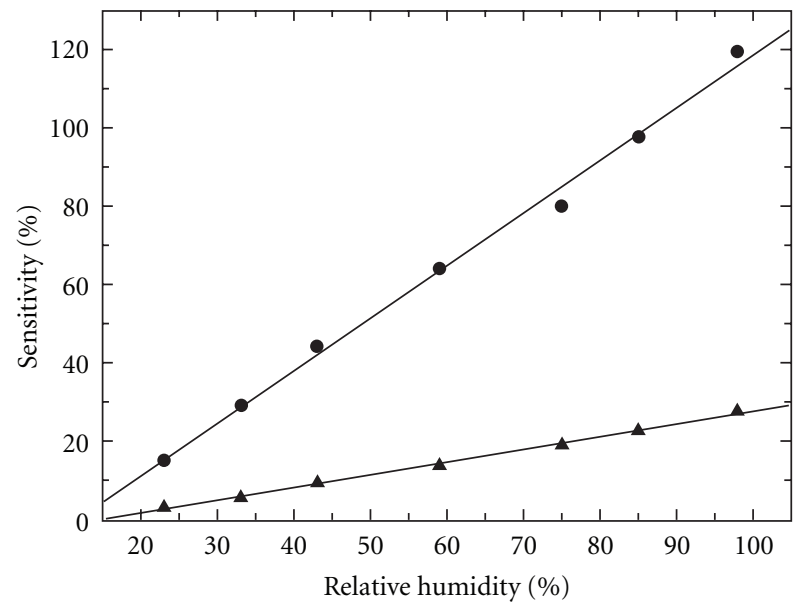

- Untreated MWCNTs humidity sensor

- Treated MWCNTs humidity sensor

FIGURE 3: The sensitivity factor S of untreated and treated MWCNT humidity sensors.

amount of water molecules adsorbed on CNTs between the humidification process and the desiccation process at a same ambient $\mathrm{RH}$, causing the different resistance at a same $\mathrm{RH}$.

3.3. Response and Recover Properties. Several important parameters for sensor devices are response time, recover time, and reproducibility. To investigate these properties, the dynamic testing of the untreated and chemically treated MWCNT sensors at a constant RH is performed. The response time for the absorption and desorption curves measured at $20^{\circ} \mathrm{C}$ for the sensors is shown in Figure 4. The response time to continuous humidification from 33\% to $98 \% \mathrm{RH}$ is 20 and $50 \mathrm{~s}$ for the untreated and treated MWCNT sensors, respectively. While the recover time from $98 \%$ to $33 \% \mathrm{RH}$ is 40 and $140 \mathrm{~s}$ for the treated and untreated MWCNT sensors, respectively. Further testing after three additional cycles demonstrates good reproducibility of the treated MWCNT sensors. The response and recovery time are much shorter than that of other sensors made of complex oxides, such as In-doped $\mathrm{CaZrO}_{3}$ [11] which works at high temperature $\left(700^{\circ} \mathrm{C}\right.$ ), $\mathrm{Ba}_{1-x} \mathrm{La}_{x} \mathrm{SnO}_{3}$ (both 60 s) [12] and $\mathrm{Sr}$ added $\mathrm{BaAl}_{2} \mathrm{O}_{4}(120 \mathrm{~S}$ and $50 \mathrm{~s})$ [13] and other materials [14-16]. Therefore, the sensor made of the treated MWCNTs can be regarded as a fast response humidity sensor.

In case of humidity sensors, the recovery time is always higher than the response time $[5,9,17]$, agreeing with our results. The long recover time can be attributed to slow desorption process of water molecules from CNTs at ambient temperature. As the usual response and recover time are tens and hundreds seconds, the quick response and recover property of the treated MWCNTs sensor has an advantage for practical applications.

3.4. Stabilization. The resistance variations with time for two kinds of samples are shown in Figure 5. The measurements were repeated at $20^{\circ} \mathrm{C}$, every 5 days for one month. Slight or little resistance variation have been observed in both untreated and treated samples at each humidity region for one month, indicating that both the treated and untreated MWCNTs sensors are relatively stable to exposure to water vapor in air.

3.5. Humidity Sensing Mechanism. The origin of the humidity sensing effect in MWCNTs films may be caused by adsorption to water molecules. Before our experiment, the MWCNTs appear p-type semiconductor behavior tested by Hall effect experiment. For p-type MWCNTs, the adsorbed water molecules donate electrons to the valence band, thereby decreasing the number of holes and increasing the separation between the Fermi level and valence band [4, 7], and resulting in increase of the electrical resistance (see Figure 2). Although there is a humidity sensing effect to untreated MWCNTs, it is much weaker than that of treated MWCNTs. Chemical treatment makes carbon nanotubes 


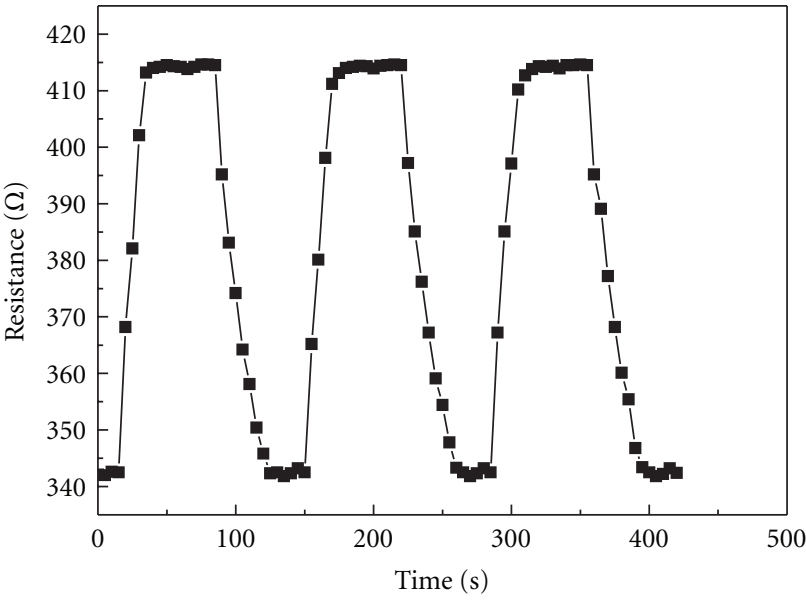

(a)

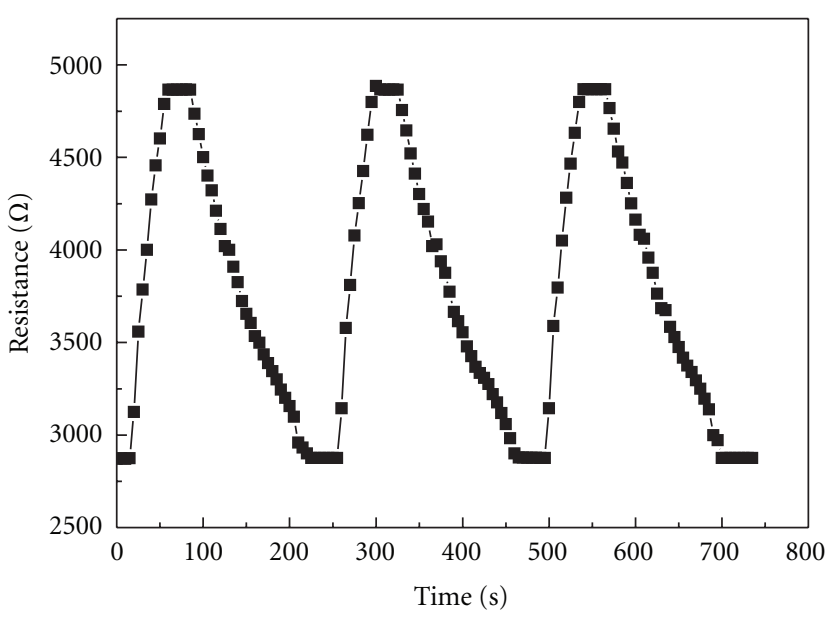

(b)

FIGURE 4: Dynamic response of untreated (a) and treated (b) MWCNT humidity sensors to humidity.

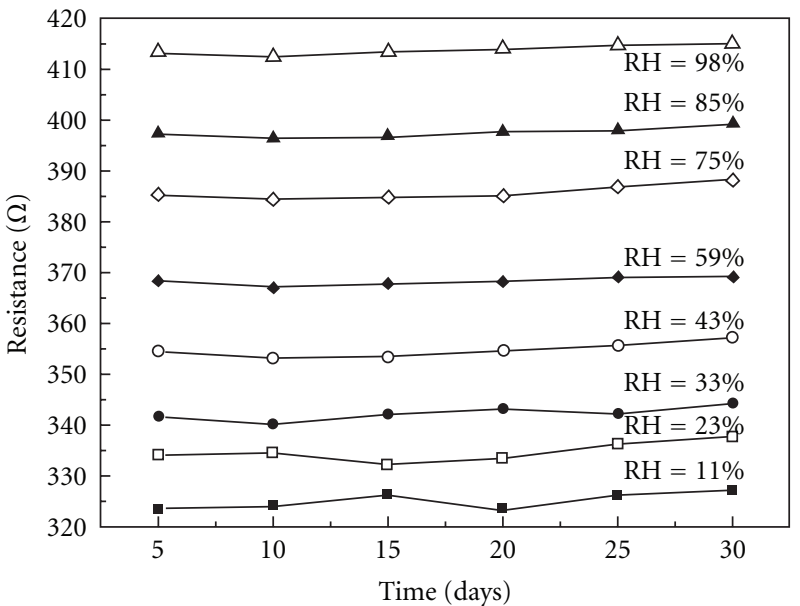

(a)

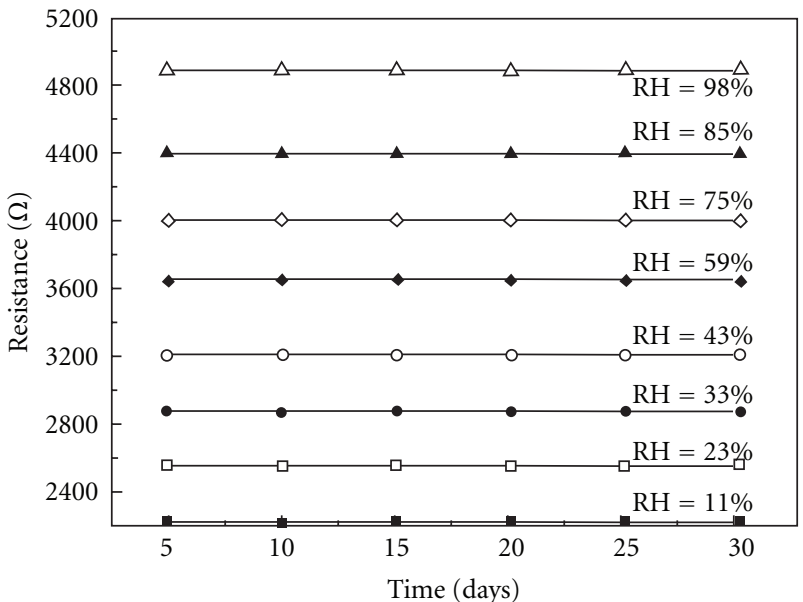

(b)

FIGURE 5: Resistance variations with time for the sensors at various RH levels: untreated (a) and treated (b) MWCNT humidity sensor.

shorten, more ends open, and more defects, which makes water molecules adsorb tubes easily. As MWCNTs could connect with lots of hydroxyl on its defects and open ends by chemical treatment, they could act as sites of adsorption to water molecules. Water molecules could be adsorbed on MWCNTs for the hydrogen in $\mathrm{H}_{2} \mathrm{O}$ molecule could form a weak bond with one of the surface $\mathrm{C}$ atoms. Pati et al. [8] reported that charge can transfer between the adsorbate and the CNTs. A quantitative analysis based on Mulliken approach shows a charge transfer of $0.03 \mathrm{e}^{-}$from the single $\mathrm{H}_{2} \mathrm{O}$ molecule to the CNTs [7]. The more water molecules can be adsorbed on the surface, intertubes, and ends after chemical treatment, the more charge transfer happens between the water molecules and CNTs. The presence of defects after chemical treatment may also reduce the conductivity of MWCNTs. Therefore, the humidity sensing characteristics of MWCNTs films is greatly enhanced after chemical treatment.

\section{Conclusions}

CNTs have been investigated as a new humidity sensitive material. The properties of the chemically treated CNT humidity sensors are discussed and compared with that of the untreated CNT sensors. The sensitivity of CNTs to humidity can be enhanced with chemical treatment. The charge transfer from absorbed water molecules to CNTs is a main reason for the humidity sensing properties. The treated CNT humidity sensor exhibited good sensitivity, linear and quick response, and excellent stability in different $\mathrm{RH}$ atmosphere, which demonstrate that it could be used as a good humidity sensor in practice applications.

\section{Acknowledgments}

This work has been funded by the NSFC (60976055), and Postgraduates' Innovative Training Project (S-09109) of the 
3rd-211 Project, and the large-scale equipment sharing fund of Chongqing University.

\section{References}

[1] S. Iijima, "Helical microtubules of graphitic carbon," Nature, vol. 354, pp. 56-58, 1991.

[2] M. Cinke, J. Li, B. Chen et al., "Pore structure of raw and purified HiPco single-walled carbon nanotubes," Chemical Physics Letters, vol. 365, no. 1-2, pp. 69-74, 2002.

[3] C. K. W. Adu, G. U. Sumanasekera, B. K. Pradhan, H. E. Romero, and P. C. Eklund, "Carbon nanotubes: a thermoelectric nano-nose," Chemical Physics Letters, vol. 337, no. 1-3, pp. 31-35, 2001.

[4] J. Kong, N. R. Franklin, C. Zhou et al., "Nanotube molecular wires as chemical sensors," Science, vol. 287, no. 5453, pp. 622$625,2000$.

[5] O. K. Varghese, P. D. Kichambre, D. Gong, K. G. Ong, E. C. Dickey, and C. A. Grimes, "Gas sensing characteristics of multi-wall carbon nanotubes," Sensors and Actuators B, vol. 81, no. 1, pp. 32-41, 2001.

[6] L. Valentini, I. Armentano, J. M. Kenny, C. Cantalini, L. Lozzi, and S. Santucci, "Sensors for sub-ppm $\mathrm{NO}_{2}$ gas detection based on carbon nanotube thin films," Applied Physics Letters, vol. 82, no. 6, pp. 961-963, 2003.

[7] A. Zahab, L. Spina, P. Poncharal, and C. Marlière, "Watervapor effect on the electrical conductivity of a single-walled carbon nanotube mat," Physical Review B, vol. 62, no. 15, pp. 10000-10003, 2000.

[8] R. Pati, Y. Zhang, S. K. Nayak, and P. M. Ajayan, "Effect of $\mathrm{H}_{2} \mathrm{O}$ adsorption on electron transport in a carbon nanotube," Applied Physics Letters, vol. 81, no. 14, pp. 2638-2640, 2002.

[9] C. Cantalini, L. Valentini, I. Armentano, L. Lozzi, J. M. Kenny, and S. Santucci, "Sensitivity to $\mathrm{NO}_{2}$ and cross-sensitivity analysis to $\mathrm{NH}_{3}$, ethanol and humidity of carbon nanotubes thin film prepared by PECVD," Sensors and Actuators B, vol. 95, no. 1-3, pp. 195-202, 2003.

[10] C. J. Lee, J. Park, S. Han, and J. Ihm, "Growth and field emission of carbon nanotubes on sodalime glass at $550^{\circ} \mathrm{C}$ using thermal chemical vapor deposition," Chemical Physics Letters, vol. 337, no. 4-6, pp. 398-402, 2001.

[11] M. H. Zhou and A. Ahamad, "Sol—gel processing of in-doped $\mathrm{CaZrO}_{3}$ solid electrolyte and the impedimetric sensing characteristics of humidity and hydrogen," Sensors and Actuators B, vol. 129, pp. 205-209, 2008.

[12] S. Upadhyay and P. Kavitha, "Lanthanum doped barium stannate for humidity sensor," Materials Letters, vol. 61, no. 8-9, pp. 1912-1915, 2007.

[13] J. J. Vijaya, L. J. Kennedy, G. Sekaran, and K. S. Nagaraja, "Synthesis, characterization and humidity sensing properties of $\mathrm{Sr}(\mathrm{II})$-added $\mathrm{BaAl}_{2} \mathrm{O}_{4}$ composites," Sensors and Actuators B, vol. 124, no. 2, pp. 542-548, 2007.

[14] Z. Zhang, C. Hu, Y. Xiong, R. Yang, and Z. L. Wang, "Synthesis of Ba-doped $\mathrm{CeO}_{2}$ nanowires and their application as humidity sensors," Nanotechnology, vol. 18, no. 46, Article ID 465504, 2007.

[15] W. Yan, C. Hu, Y. Xi et al., "ZnSe nanorods prepared in hydroxide-melts and their application as a humidity sensor," Materials Research Bulletin, vol. 44, no. 6, pp. 1205-1208, 2009.

[16] M. Zhang, C. Hu, H. Liu, Y. Xiong, and Z. Zhang, "A rapidresponse humidity sensor based on $\mathrm{BaNbO}_{3}$ nanocrystals," Sensors and Actuators B, vol. 136, no. 1, pp. 128-132, 2009.
[17] Z.-H. Wu, W.-L. Wang, K.-J. Liao et al., "Study on the humidity sensitive behavior of multiwalled carbon nanotubes," Chinese Physical Society, vol. 53, no. 10, pp. 3462-3466, 2004. 

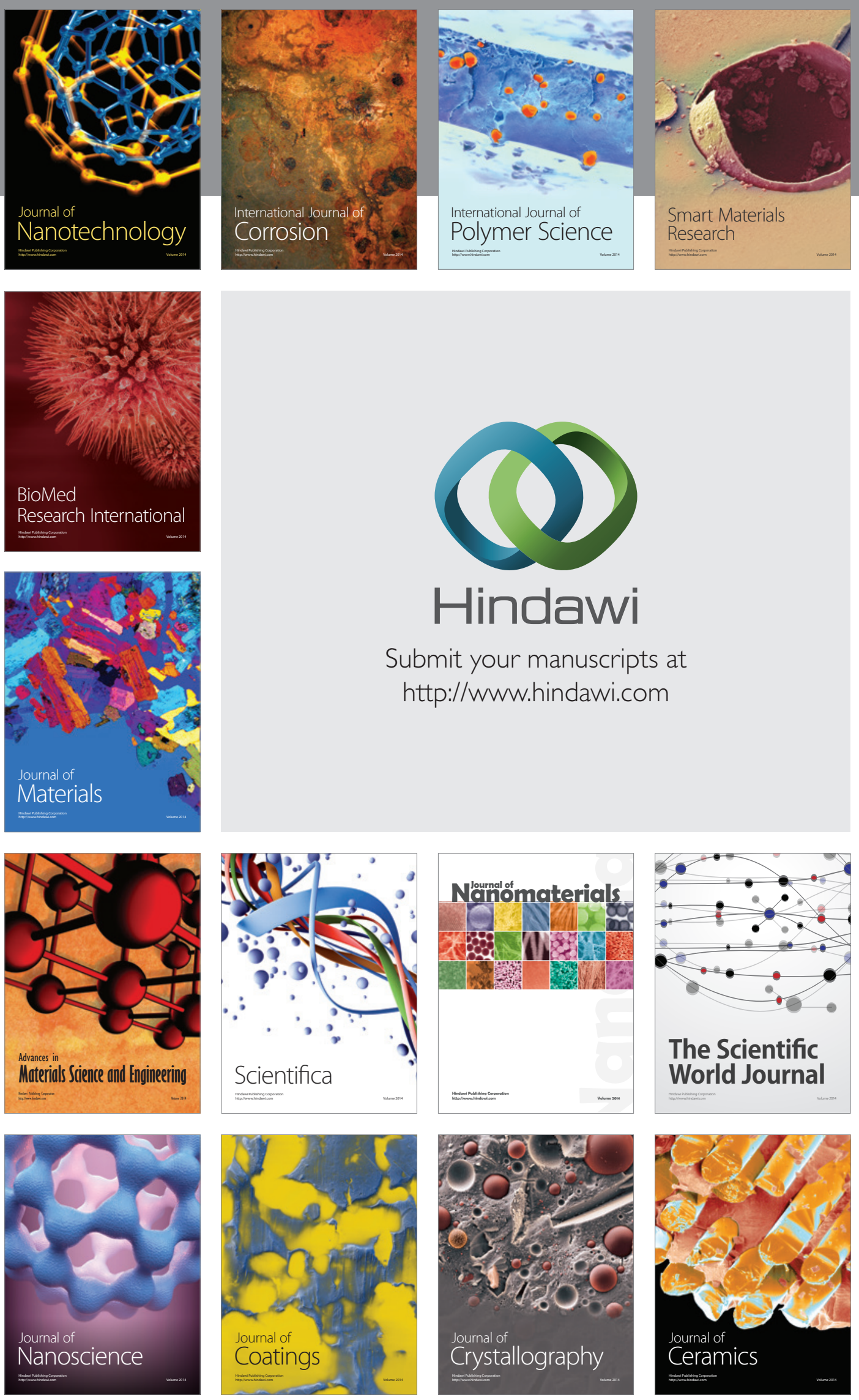

The Scientific World Journal

Submit your manuscripts at

http://www.hindawi.com

\section{World Journal}

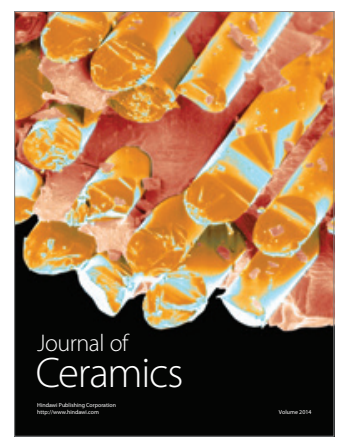

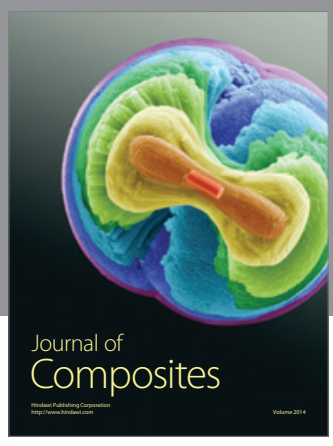
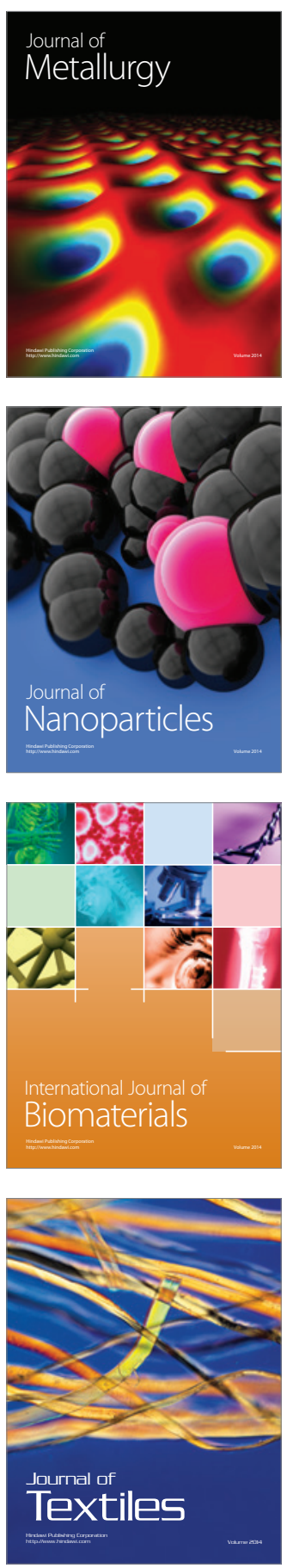